\title{
MODEL STAR DENGAN BOBOT SERAGAM SEBAGAI PENDETEKSI DEBIT AIR SUNGAI CITARUM
}

\author{
Kankan Parmikanti \\ Departemen Matematika FMIPA Universitas Padjadjaran \\ parmikanti@unpad.ac.id \\ Khafsah Joebaedi \\ Departemen Matematika FMIPA Universitas Padjadjaran \\ Iin Irianingsih \\ Departemen Matematika FMIPA Universitas Padjadjaran
}

\begin{abstract}
Lately when rainfall in West Java is quite high, the problem of flooding caused by overflowing of the river has always been a trending topic of regional leaders. Whatever the causes of flooding, be it because a lot of waste dumped in rivers or due to illegal logging of trees in the forest, the river water discharge increased rapidly, and overflowed into public housing. Based on the above, it should be made a model that can predict the water discharge of the river from time to time in various locations in West Java. In this paper will be presented studies Space Time Auto Regression models STAR $(1,1)$ to model the problem of water discharge some rivers in West Java, which can be useful for predicting the discharge of river water in the future. By using Least Squares Method as predictors for the parameters, as well as assuming a uniform weighting matrix, the result that the water discharge of a river in addition affected by the river water flow at an earlier time, it is also influenced by the discharge of river water around.
\end{abstract}

Keywords: Models, OLS, STAR, River.

ABSTRAK. Akhir-akhir ini ketika curah hujan di Jawa Barat cukup tinggi, masalah banjir yang disebabkan meluapnya air sungai senantiasa menjadi trending topik para pimpinan daerah. Apapun penyebab banjir, baik itu karena banyak sampah yang dibuang ke sungai atau karena banyaknya penebangan liar pohon-pohon di hutan, yang jelas debit air sungai meningkat dengan pesat, dan meluap ke perumahan rakyat. Berdasarkan hal di atas, perlu dibuat suatu model yang dapat memprediksi debit air sungai dari waktu ke waktu di berbagai lokasi di wilayah Jawa Barat. Dalam makalah ini akan disajikan kajian model Space Time Auto Regression STAR $(1,1)$ untuk memodelkan masalah debit air beberapa sungai di Jawa Barat yang dapat berguna untuk memprediksi debit air sungai di masa yang akan datang. Dengan menggunakan Metode Kuadrat Terkecil sebagai penaksir parameternya, serta dengan mengasumsikan matriks bobot yang seragam, diperoleh hasil bahwa debit air suatu sungai selain dipengaruhi oleh debit air sungai tersebut pada waktu sebelumnya, juga dipengaruhi oleh debit air sungai di sekitarnya.

Kata Kunci: Model, MKT, Sungai, STAR. 


\section{PENDAHULUAN}

Akhir-akhir ini ketika curah hujan di Jawa Barat cukup tinggi, masalah banjir yang disebabkan meluapnya air sungai senantiasa menjadi trending topik para pimpinan daerah. Berbagai kemungkinan penyebab meluapnya air sungai selalu dicari untuk mendapatkan solusi preventif mengatasi banjir tersebut. Hasil analisis secara umum, penyebab banjir adalah karena banyak sampah yang dibuang ke sungai, atau karena banyaknya penebangan liar pohon-pohon di hutan. Namun demikian apapun penyebabnya yang jelas debit air sungai meningkat dengan pesat, dan ahirnya meluap ke perumahan rakyat dan ke jalan raya. Hal inilah yang membuat pemerintah menjadi repot memikirkan penanggulangannya. Berdasarkan hal di atas, untuk meminimalisir akibat banjir perlu adanya pendeteksi secara dini untuk memprediksi debit air sungai yang akan datang melalui pengamatan dari waktu ke waktu di berbagai lokasi sungai di wilayah Jawa Barat, khususnya sungai Citarum di Kabupaten Bandung.

Di sisi lain, secara teoritis terdapat banyak model yang bisa digunakan untuk memperkirakan debit sungai dari waktu ke waktu, yaitu yang berkaitan dengan deret waktu (time series). Debit air sungai merupakan masalah deret waktu, yang dapat dimodelkan dengan model AutoRegresi atau disingkat dengan AR, yaitu model yang cukup sederhana, sehingga lebih dikenal dan sering digunakan hingga saat ini. Untuk data multivariat, di mana debit air disuatu lokasi dipengaruhi oleh sungai-sungai lain disekitarnya, model AR ini dapat dikembangkan menjadi model Vektor Auto Regresi, atau menjadi model Space Time Auto Regression (STAR). (Borovkov dkk, 2002).

Dengan demikian penerapan model deret waktu merupakan masalah yang menarik untuk dikaji baik secara teori maupun aplikasi dengan menerapkannya pada data lapangan, khususnya untuk melihat fenomena debit air sungai di Jawa Barat. Mengingat di Kabupaten Bandung ada banyak sungai yang berpotensi mengakibatkan banjir, yang tiga diantaranya adalah sungai Citarum, sungai Cidurian, dan sungai Cigulung, maka dalam makalah ini akan disajikan hasil penelitian mengenai deteksi dan prediksi debit air sungai menggunakan model 
STAR dengan bobot seragam, di mana untuk menaksir parameternya akan menggunakan Metode Kuadrat Terkecil (MKT).

\section{TINJAUAN PUSTAKA}

Model STAR dapat digunakan untuk memodelkan masalah-masalah dalam berbagai bidang ilmu, misalnya Kyriakidis dan Journel (1999) telah menggunakannya dalam bidang geologi, Epperson (2000) menggunakan model STAR pada masalah genetika berdasarkan waktu dan lokasi, Giacomini dan Granger (2004) memanfaatkan Model STAR secara luas di bidang ekonomi, serta Kamarianakis dan Prastacos (2005) menggunakan model ini untuk menyelesaikan masalah transportasi, Suhartono dan Dhoriva Urwatul Wutsqa (2007) membandingkan model STAR dengan VAR dalam pembuatan model berkaitan dengan produksi perkebunan teh, sedangkan Henny Dwi Khoirun Nisa (2010) menggunakan model GSTAR untuk meramalkan debit air sungai Brantas.

\subsection{Time Series}

Ada dua jenis model peramalan yang utama, yaitu model regresi dan model deret waktu (time series). Jika dalam model regresi peramalan masa depan tidak harus didasarkan pada masa lalu, misalnya hubungan antara tinggi badan dan berat badan ideal, maka dalam model deret waktu peramalan masa depan dilakukan berdasarkan nilai masa lalu. Tujuan metode peramalan deret waktu adalah menemukan pola atau model dalam deret data historis dan mengekstrapolasikan pola tersebut ke masa depan (Ruchjana, B. N, 2002). Tujuan dari analisis deret waktu secara umum meliputi dua hal, yaitu memahami atau memodelkan proses stokastik yang timbul pada rangkaian observasi dan memperkirakan nilai masa depan berdasarkan data deret waktu yang telah terjadi (Wei, W.W.S, 1989).

\subsection{Model Autoregresi dan Vektor Autoregresi}

Salah satu bentuk representasi untuk menuliskan sebuah proses $Z(t)$ yang sering digunakan dalam analisis time series adalah bentuk representasi yang 
disebut dengan representasi autoregresi (AR), di mana nilai $Z$ pada waktu $t$ dinyatakan sebagai kombinasi linear dari nilai-nilai $\mathrm{Z}$ pada waktu sebelumnya ditambah sebuah faktor kesalahan. Model tersebut adalah

$$
Z(t)=\phi_{1} Z(t-1)+\phi_{2} Z(t-2)+\phi_{3} Z(t-3)+\ldots+\phi_{p} Z(t-p)+\boldsymbol{e}(t)
$$

Untuk autoregresi orde pertama yaitu $\operatorname{AR}(1)$, di mana nilai $Z$ pada waktu $t$ dinyatakan sebagai nilai $\mathrm{Z}$ pada waktu satu periode sebelumnya. Model ditulis sebagai

$$
Z(t)=\phi_{1} Z(t-1)+\boldsymbol{e}(t)
$$

dengan $\phi_{1}$ adalah parameter yang harus ditaksir.

Dalam banyak kesempatan, data time series sering kali merupakan hasil observasi dari beberapa lokasi yang berbeda, misalnya $N$ lokasi. Dalam hal ini model yang cocok digunakan bukan lagi AR, tetapi model Vektor Auto Regresi yang disingkat VAR dengan $N$ buah variabel Model VAR berorde $p$ ditulis $\operatorname{VAR}(p)$ artinya ketergantungan terhadap $p$ waktu sebelumnya.

$$
\boldsymbol{Z}(t)=\phi_{1} \boldsymbol{Z}(t-1)+\phi_{2} \boldsymbol{Z}(t-2)+\phi_{3} \boldsymbol{Z}(t-3)+\ldots+\phi_{i} \boldsymbol{Z}(t-i)+\boldsymbol{e}(t)
$$

Untuk VAR(1) model ber orde $p=1$ dengan banyaknya lokasi $N=2$, model menjadi:

$$
\left\{\begin{array}{l}
\mathrm{z}_{1}(t)=\phi_{11} z_{1}(t-1)+\phi_{12} z_{2}(t-1)+e_{1}(t) \\
\mathrm{z}_{2}(t)=\phi_{21} z_{1}(t-1)+\phi_{22} z_{2}(t-1)+e_{2}(t)
\end{array}\right.
$$

Artinya bahwa nilai observasi pada waktu $t$ di lokasi 1, dipengaruhi oleh hasil observasi waktu $(t-1)$ di lokasi 1 dan di lokasi 2. Demikian pula nilai observasi pada waktu $t$ di lokasi 2, juga dipengaruhi oleh hasil observasi waktu $(t-1)$ di lokasi 1 dan di lokasi 2 (Wei,1994).

\section{METODE PENELITIAN}

Untuk menentukan model yang dapat digunakan untuk mendeteksi dan memprediksi debit air sungai, akan digunakan model STAR $(1,1)$ yaitu dengan lag waktu 1 (satu periode sebelumnya) dan lag spasial 1 (satu kelompok penelitian). Bobot yang akan digunakan adalah bobot seragam, dan metode penaksir parameternya adalah MKT. 
Model STAR(1,1) dinyatakan:

$$
\mathbf{z}(t)=\phi_{01} \mathbf{z}(t-1)+\phi_{11} W \mathbf{z}(t-1)+\boldsymbol{e}(t)
$$

dengan $\quad \mathbf{z}(t)$ : vektor pengamatan $(p \times 1)$ dari $p$ lokasi pada waktut.

$W$ : matriks bobot ( $p \times p)$ pada lagspasial 1.

$t$ : waktu pengamatan $(t=1,2,3,4, \ldots, n)$.

$\phi_{01}$ : parameter model pada lagspasial 0 dan lagwaktu 1.

$\phi_{11}$ : parameter model pada lagspasial 1 dan lagwaktu 1.

dan vektor error: $\quad \boldsymbol{e}(t) \stackrel{\text { iid }}{\sim} \mathrm{N}\left(\mathbf{0}, \sigma^{2} \mathbf{I}_{N}\right)$.

iid $=$ independent identically distributied

Persamaan model STAR $(1,1)$ untuk 3 lokasi dapat disajikan dalam bentuk matriks $\left[\begin{array}{l}\mathrm{z}_{1}(t) \\ z_{2}(t) \\ z_{3}(t)\end{array}\right]=\phi_{01}\left[\begin{array}{l}z_{1}(t-1) \\ z_{2}(t-1) \\ z_{3}(t-1)\end{array}\right]+\phi_{11}\left[\begin{array}{ccc}0 & w_{12} & w_{13} \\ w_{21} & 0 & w_{23} \\ w_{31} & w_{32} & 0\end{array}\right]\left[\begin{array}{l}z_{1}(t-1) \\ z_{2}(t-1) \\ z_{3}(t-1)\end{array}\right]+\left[\begin{array}{l}e_{1}(t) \\ e_{2}(t) \\ e_{3}(t)\end{array}\right]$.

Secara umum persamaan (2) di atas dapat ditulis sebagai:

$$
z(t)=\left[\begin{array}{ll}
z(t-1) & W z(t-1)
\end{array}\right]\left[\begin{array}{l}
\phi_{01} \\
\phi_{11}
\end{array}\right]+e(t)
$$

atau dalam bentuk persamaan linear dapat disajikan sebagai:

$$
\left.\begin{array}{l}
\mathrm{z}_{1}(t)=\phi_{01} z_{1}(t-1)+\phi_{11} w_{12} z_{2}(t-1)+\phi_{11} w_{13} z_{3}(t-1)+e_{1}(t) \\
\mathrm{z}_{2}(t)=\phi_{01} z_{2}(t-1)+\phi_{11} w_{21} z_{1}(t-1)+\phi_{11} w_{23} z_{3}(t-1)+e_{2}(t) \\
\mathrm{z}_{3}(t)=\phi_{01} z_{3}(t-1)+\phi_{11} w_{31} z_{1}(t-1)+\phi_{11} w_{32} z_{2}(t-1)+e_{3}(t) .
\end{array}\right\}
$$

Selanjutnya untuk menaksir parameter $\phi_{01}$ dan $\phi_{11}$, digunakan Metode Kuadrat Terkecil. Hal ini sangat memungkinkan karena Model STAR(1,1) pada (3) dapat dituliskan sebagai

$$
\left[\begin{array}{l}
z_{1}(t) \\
z_{2}(t) \\
z_{3}(t)
\end{array}\right]=\left[\begin{array}{ll}
z_{1}(t-1) & w_{12} z_{2}(t-1)+w_{13} z_{3}(t-1) \\
z_{2}(t-1) & w_{21} z_{1}(t-1)+w_{23} z_{3}(t-1) \\
z_{3}(t-1) & w_{31} z_{1}(t-1)+w_{32} z_{2}(t-1)
\end{array}\right] \cdot\left[\begin{array}{l}
\phi_{01} \\
\phi_{11}
\end{array}\right]+\left[\begin{array}{l}
e_{1}(t) \\
e_{2}(t) \\
e_{3}(t)
\end{array}\right]
$$

sehingga identik dengan model regresi linear

$$
\mathbf{Y}=\mathbf{X} \boldsymbol{\beta}+\boldsymbol{e}(t), \quad \boldsymbol{e}(t) \stackrel{i i d}{\sim} \mathrm{N}\left(\mathbf{0}, \sigma^{2}\right)
$$


dengan

$$
\begin{gathered}
\mathbf{Y}=\mathbf{z}(t)=\left[\begin{array}{l}
\mathrm{z}_{1}(t) \\
z_{2}(t) \\
z_{3}(t)
\end{array}\right], \\
X=\left[\begin{array}{lll}
z(t-1) & W z(t-1)
\end{array}\right]=\left[\begin{array}{ll}
z_{1}(t-1) & w_{12} z_{2}(t-1)+w_{13} z_{3}(t-1) \\
z_{2}(t-1) & w_{21} z_{1}(t-1)+w_{23} z_{3}(t-1) \\
z_{3}(t-1) & w_{31} z_{1}(t-1)+w_{32} z_{2}(t-1)
\end{array}\right],
\end{gathered}
$$

dan $\boldsymbol{\beta}=\left[\begin{array}{l}\phi_{01} \\ \phi_{11}\end{array}\right]$. Dengan meminimumkan kuadrat eror, maka diperoleh rumus penaksir parameter

$$
\boldsymbol{\beta}=\left[\begin{array}{l}
\phi_{01} \\
\phi_{11}
\end{array}\right]=\left(X^{T} \cdot X\right)^{-1} X^{T} Y
$$

\section{HASIL DAN PEMBAHASAN}

Data yang diperoleh merupakan data debit sungai Citarum hulu dari 3 lokasi daerah aliran sungai Citarum sebagai berikut:

Z1: Daerah aliran sungai Cidurian-Sukapada

Z2: Daerah aliran sungai Cigulung-Maribaya

Z3: Daerah aliran sungai Citarum-Majalaya

Data diperoleh dari PUSAIR Bandung yang merupakan data debit sungai Citarum hulu tahun 2009 hingga tahun 2012. Data yang diteliti berupa data rekap harian debit sungai Citarum.

Tabel 1. Sebaran data debit air sungai hasil 32 pengamatan

\begin{tabular}{|c|c|c|c|c|}
\hline Lokasi & Minimum & Rata-rata & STD DEV & Makasimum \\
\hline Z1 & 17,1 & 24,96 & 5,65 & 35,95 \\
\hline Z2 & $\mathbf{2 4 , 5 8}$ & 46,76 & 18,74 & 61,93 \\
\hline Z3 & $\mathbf{5 7 , 9 5}$ & 195,11 & 209,06 & 438 \\
\hline
\end{tabular}


Berikut adalah plot ACF dan PACF
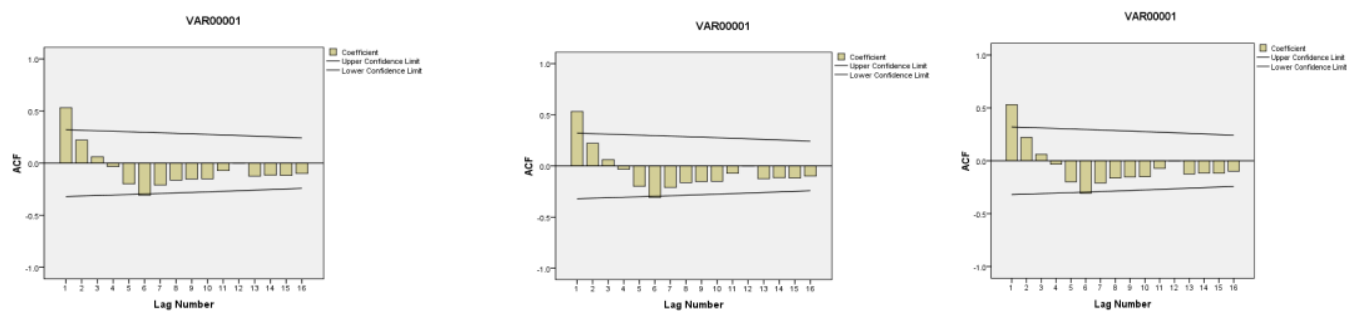

Gambar 1. ACF $Z_{1}, Z_{2}, Z_{3}$
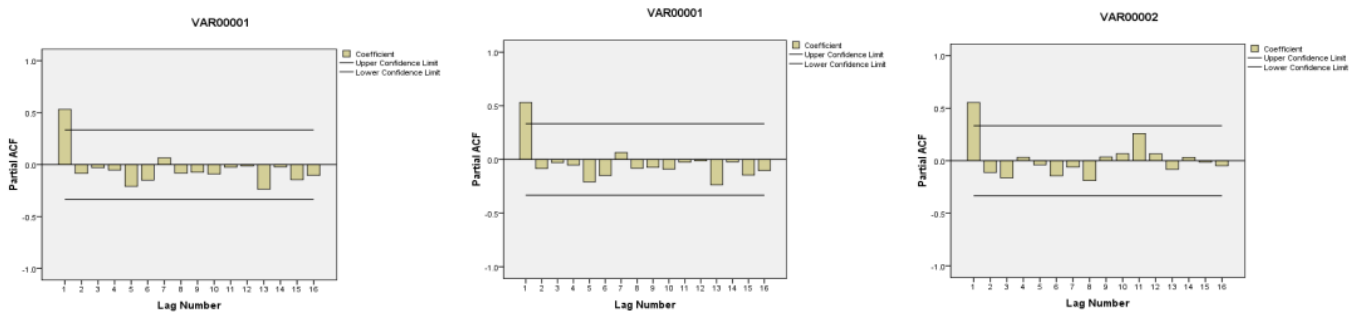

Gambar 2. PACF $Z_{1}, Z_{2}, Z_{3}$

Dari ACF dan PACF terlihat bahwa data stasioner terpotong di lag-1, yang artinya metode STAR berorde 1 atau $\operatorname{STAR}(1,1)$. Selanjutnya dengan mengambil matriks bobot seragam

$$
\mathrm{W}=\left[\begin{array}{ccc}
0 & w_{12} & w_{13} \\
w_{21} & 0 & w_{23} \\
w_{31} & w_{32} & 0
\end{array}\right]=\left[\begin{array}{ccc}
0 & 0,5 & 0,5 \\
0,5 & 0 & 0,5 \\
0,5 & 0,5 & 0
\end{array}\right]
$$

dan dengan menggunakan rumus (4) diperoleh penaksir parameter:

$$
\beta=\left[\begin{array}{l}
\phi_{01} \\
\phi_{11}
\end{array}\right]=\left[\begin{array}{l}
0,877 \\
0,039
\end{array}\right]
$$

Dengan mensubstitusikan nilai penaksir parameter tersebut ke persamaan (3), maka diperoleh model STAR(1,1) yang dimaksud adalah:

$$
\left\{\begin{array}{c}
z_{1}(t)=0,877 z_{1}(t-1)+0,0195 z_{2}(t-1)+0,0195 z_{3}(t-1) \\
z_{2}(t)=0,877 z_{2}(t-1)+0,0195 z_{1}(t-1)+0,0195 z_{3}(t-1) \\
z_{3}(t)=0,877 z_{3}(t-1)+0,0195 z_{1}(t-1)+0,0195 z_{2}(t-1)
\end{array}\right.
$$

\section{KESIMPULAN DAN SARAN}

Berdasarkan model yang diperoleh, maka seperti dugaan sebelumnya bahwa debit air suatu sungai pada periode saat ini, selain dipengaruhi oleh debit 
air sungai tersebut pada satu periode sebelumnya, juga dipengaruhi debit air sungai-sungai yang lain di sekitarnya pada satu periode sebelumnya.

Adapun saran yang kami sampaikan adalah untuk mengembangkan model time series menjadi GSTAR, yaitu model STAR yang digeneralisasi. Selain itu bisa dicoba dengan bobot yang tidak seragam atau menggunakan model VAR, sehingga dapat diperoleh model yang terbaik.

\section{UCAPAN TERIMAKASIH}

Kami tim peneliti mengucapkan terimakasih yang sebesar-besarnya kepada Rektor Universitas Padjadjaran dan Direktur DPRM yang telah memberi kesempatan dengan mendanai penelitian ini.

\section{DAFTAR PUSTAKA}

Borovkova, S.A, Lopuhaa, H.P, dan Ruchjana, B.N, Generalized, STAR Model with Experimental Weights, dalam M. Staionopolous dan G.Toulomi (eds.), Proceeding of the $17^{\text {th }}$ International Workshop on Statistical Modelling, 2002, Chania, 139-147.

Nisa, H. D. K., Peramalan Debit Air Sungai Brantas Dengan Model GSTAR dan ARIMA, Jurusan Matematika ITS Surabaya, 2010.

Ruchjana, B. N., The Stationary of The Space Time Autoregressive Model, Majalah Ilmiah Himpunan Matematika Indonesia (MIHMI), 8(2) (2002), 151-159.

Ruchjana, B. N., Suatu Model Generalisasi SpaceTime Autoregresi (GSTAR) Orde1 dan Aplikasinya pada Data Produksi Minyak Bumi, Disertasi Program S3 Matematika ITB, Tidak Dipublikasikan, ITB, 2002.

Suhartono dan Wutsqa, D. U., Perbandingan Model VAR dan STAR pada Peramalan Produksi Teh di Jawa Barat, 2007.

Wei, W.W.S., Time Series Analysis and Multivariate Methods, Addison Wesley Publishing, Company, Inc. New York, 1994. 